\title{
PRODUCCIÓN DE BIOETANOL A NIVEL BANCO USANDO INSUMOS NACIONALES: CAÑA DE AZÚCAR Y LEVADURA DE UVA QUEBRANTA
}

\author{
BIOETHANOL PRODUCTION AT BANK SCALE USING \\ NATIONAL INPUTS: SUGAR CANE AND \\ QUEBRANTA GRAPE'S YEAST
}

\author{
Mario Ricardo De La Cruz Azabache ${ }^{1}$, Emerson Alcides Collado Domínguez ${ }^{2}$, \\ César Lagos Liberato ${ }^{3}$, Jacques Ramesh Barrueto Yanque ${ }^{4}$
}

\begin{abstract}
RESUMEN
El alcohol carburante, bioetanol anhidro desnaturalizado o simplemente bioetanol se puede obtener de diversas materias primas renovables, tales como sustratos portadores de azúcares simples, amiláceos y lignocelulósicos, siendo necesario para ello el empleo de microorganismos específicos (biomasa) que sinteticen la materia orgánica contenida en las mismas. Este trabajo se enfoca en la obtención de bioetanol hidratado (etanol al 94,8\% en volumen, antes del punto azeotrópico) a partir de caña de azúcar usando levadura de uva quebranta, subproducto del proceso Pisco-UNI. Dicho bioetanol hidratado obtenido podrá luego ser empleado como insumo principal para la producción de bioetanol (deshidratación), biodiésel (transesterificación), entre otros. Los resultados demostraron satisfactoriamente el objetivo buscado, así como se lograron mejoras en la eficiencia del proceso por medio de un tratamiento previo, tanto del jugo de caña de azúcar como de la levadura empleada, permitiendo tener de esta manera una base científica para el diseño de un proceso no convencional en la producción de bioetanol hidratado.
\end{abstract}

Palabras claves.- Bioetanol, Caña de azúcar, Levadura de uva quebranta.

\begin{abstract}
The alcohol fuel, denatured anhydrous bioethanol or just bioethanol can be obtained from different renewable raw materials, such as substrates bearing simple sugars, starch and lignocellulose, requiring the use of specific microorganisms (biomass) that synthesize the organic matter contained therein. This work focuses on obtaining hydrated bioethanol (ethanol at 94,8 \% by volume, just before azeotropic point) from sugar cane by using quebranta grape's yeast, byproduct of Pisco-UNI process. The hydrated bioethanol obtained could then be used as a main input for the production of bioethanol (dehydration), biodiesel (transesterification), among others. The results demonstrated the desired objective satisfactorily, as well as achieved obtaining improvements in the process efficiency through pretreatment, both the sugar cane juice and the yeast used, allowing to have by this way a scientific basis for the design of an unconventional process to produce hydrated bioethanol.
\end{abstract}

Keywords.- Bioethanol, Sugar cane, Quebranta grape's yeast.

\footnotetext{
${ }^{1}$ MSc. Ingeniero investigador de la Facultad de Ingeniería Química y Textil de la Universidad Nacional de Ingeniería, ${ }^{2}$ Ingeniero de la Facultad Ingeniería Química y Textil de la Universidad Nacional de Ingeniería, ${ }^{3}$ Ingeniero de la Facultad Ingeniería Química y Textil de la Universidad Nacional de Ingeniería, ${ }^{4}$ Tesista de la Facultad de Ingeniería Química y Textil Universidad Nacional de Ingeniería,
} 


\section{INTRODUCCIÓN}

El mundo encara el agotamiento progresivo de sus recursos energéticos basados mayoritariamente en combustibles no renovables. Al mismo tiempo, el consumo de energía aumenta a ritmos cada vez más crecientes, así como hay una necesidad de preservar el ambiente y mitigar el proceso de cambio climático. Todos estos hechos sustentan la búsqueda de fuentes alternativas de energía, de preferencia, no contaminantes y renovables.

Dentro de este contexto, la biotecnología ofrece múltiples alternativas tecnológicas, una de las cuales está orientada a la generación de biocombustibles, tales como el biodiésel y el bioetanol, siendo este último considerado como principal enfoque para la presente investigación.

Los biocombustibles se diferencian de los combustibles tradicionales o fósiles biológicos (el petróleo y derivados) y de otras fuentes de energía (el carbón y la energía nuclear) porque éstos se consideran como renovables, es decir, que la materia prima utilizada para producir cualquier biocombustible puede ser repuesta a una tasa igual o más rápida a la que el biocombustible es consumido.

Dentro de los biocombustibles está el bioetanol, el cual, se puede obtener a partir de diferentes sustratos: portadores de azúcares simples, siendo los principales los jugos de frutas, de caña de azúcar (y melazas de ésta) y de remolacha; amiláceos, los que son ricos en almidón como el trigo, el maíz, la cebada, la avena, el centeno, el arroz, el sorgo y la yuca, entre otros; y lignocelulósicos, como la madera, bagazo de caña, residuos agrícolas y de fábricas de tableros, papel y cartón [1].

El Perú tiene la posibilidad de cosechar caña de azúcar todo el año, lo que permite tener permanentemente disponibilidad de insumo para la producción de azúcar.

En la costa peruana se produce más caña de azúcar por hectárea que en cualquier otro país del mundo: 102,4 toneladas (Brasil produce alrededor del 75 $\%$ de este valor), lo cual permite a nuestro país tener una ventaja comparativa con la posibilidad de producir bioetanol en gran escala y que, por el momento, se convierte en un producto exportable.
La producción convencional de etanol en base de caña de azúcar comprende tres etapas: preparación de mostos, fermentación y destilación.

A partir de la caña de azúcar, se extrae el jugo, el cual contiene los azúcares reductores fermentables, que luego será combinado con la biomasa procedente de las levaduras.

Con la fermentación de dicha solución, se genera dióxido de carbono y mosto fermentado, el cual se somete a destilación con el fin de obtener un alcohol de mayor pureza (bioetanol hidratado), que contiene, aproximadamente, un $5 \%$ de agua en volumen, limitado por la mezcla azeotrópica etanol-agua. En la industria brasileña se obtiene además del bioetanol hidratado, el bioetanol anhidro, el cual implica una etapa adicional en el proceso descrito: la deshidratación. Según el proceso de producción de este país, con una tonelada de caña de azúcar es posible obtener 86 litros de bioetanol hidratado [2].

La industria del Pisco-UNI, elaborado en la Facultad de Ingeniería Textil (FIQT) de la Universidad Nacional de Ingeniería (UNI), genera actualmente como subproducto una cantidad apreciable de levadura del tipo Saccharomyce cerevisiae, la cual será empleada como materia prima importante para la obtención de bioetanol hidratado en este trabajo.

Cabe resaltar que en la industria pisquera del Perú, las levaduras obtenidas son usadas como abono, alimento de ganado y, a veces, representan un problema de disposición de residuos sólidos. Precisamente, esta investigación busca dar un valor agregado a la levadura Saccharomyce cerevisiae, microrganismo importante en el proceso de fermentación.La producción nacional de bioetanol hidratado a partir de caña de azúcar usando levadura de uva quebranta es una alternativa viable, considerando los precios internacionales del petróleo [3].

La coyuntura ha generado que muchos países apunten a la producción de este tipo de combustible; y, en otros casos, en buscar proveedores.

\section{ANTECEDENTES}


El Pisco-UNI es la primera empresa spin-off que nace en el seno de la UNI como producto de la investigación e innovación tecnológica realizada en la FIQT desde el año 2004 al 2008, ayudando de esta manera a trasferir el conocimiento y la investigación científica al mundo empresarial (principalmente a la industria artesanal) buscando su aplicación directa en los procesos productivos e incluso su comercialización a nivel nacional.

Asimismo, por medio de este modelo de investigación aplicada, hoy en día se viene mejorando la comunicación entre las universidades, el mercado y la sociedad, habiéndose obtenido ya una patente de invención nacional del proceso [4].

Uno de los subproductos generados durante todo el proceso Pisco-UNI es una cantidad apreciable de levadura; en particular, levadura de uva quebranta, la cual será utilizada en este trabajo como fuente de biomasa para la degradación de la materia orgánica presente en el jugo de caña de azúcar y su transformación en bioetanol hidratado.

Dicha levadura es del tipo Saccharomyce cerevisiae, la cual es ampliamente utilizada en la industria alcoholera, por su gran capacidad de conversión de azúcares reductores a etanol.

De esta manera, se aprovecha el potencial de la levadura de uva quebranta para la obtención de bioetanol hidratado (etanol al 94,8 \% en volumen, antes del punto azeotrópico) a partir de caña de azúcar, trabajo que formó parte del proyecto global de investigación aplicada denominado "Producción de bioetanol a nivel banco usando insumos nacionales", el cual fue aprobado y desarrollado en la FIQT de la UNI desde el año 2009 al 2010 con la participación directa de los suscritos investigadores y con el apoyo de la especialidad de microbiología de la Universidad Nacional Mayor de San Marcos (UNMSM), concluyendo con el desarrollo y aprobación con excelencia de una tesis de grado [3].

Cabe señalar que el proyecto global "Producción de bioetanol a nivel banco usando insumos nacionales" tuvo como alcance final la obtención de bioetanol, para lo cual se realizó una tesis específica adicional sobre el proceso de deshidratación, aprovechando los abundantes recursos no metálicos que tiene nuestro país, tales como el caolín y/o la puzolana que fueron utilizados para la sintetización del material adsorbente, denominado zeolita $\mathrm{NaA}$ de la familia $3 \mathrm{~A}$, con el cual se logró separar el agua de la mezcla azeotrópica etanol-agua obtenida en la etapa de destilación, dado su conformación geométrica molecular, su dimensión porosa y su carácter hidrofílico.

\section{PROCEDIMIENTO EXPERIMENTAL}

El método consistió en realizar varias corridas experimentales del jugo de caña de azúcar en un reactor Batch $(45 \mathrm{~L})$ de tanque agitado a condiciones controladas y estables de operación.

En primer lugar, la caña de azúcar utilizada fue sometida a un proceso de molienda, de tal manera de obtener el jugo de la misma y el bagazo, los cuales fueron pesados por separado. Seguidamente, para lograr la fermentación de la materia orgánica contenida en dicho jugo, se inoculó la levadura de uva quebranta al $3 \%$ en volumen (Figura 1).

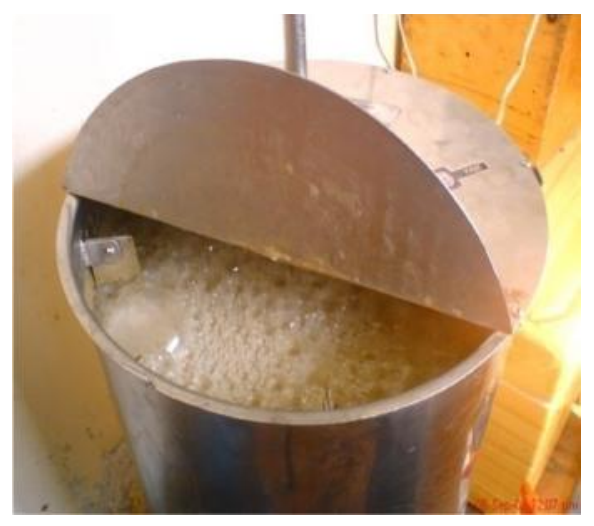

Fig. 1 Fermentación del jugo de caña de azúcar en el reactor Batch, con una capacidad de $45 \mathrm{~L}$.

Luego, el mosto fermentado fue descargado del reactor para proceder a la sedimentación por gravedad de la levadura y a su separación por decantación.

Finalmente, se procedió a realizar una destilación tipo Batch en una columna simple (una etapa) para comparar los rendimientos obtenidos ( $\mathrm{L}$ etanol / TM caña) en cada experiencia realizada (Figura 2). 


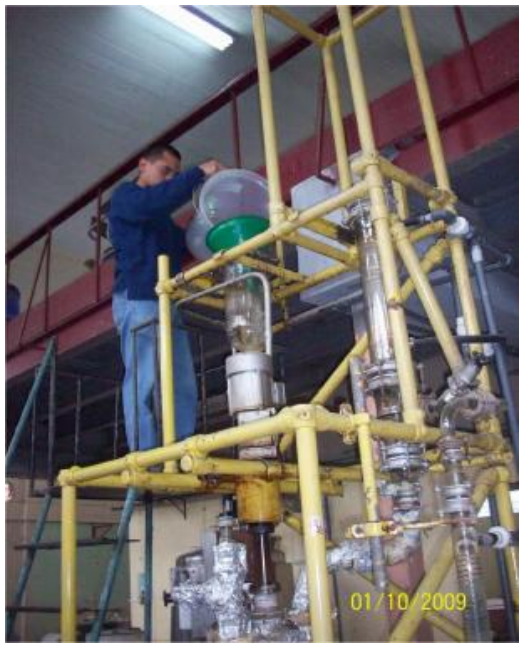

Fig.2 Destilación tipo Batch del mosto fermentado en una columna simple (una etapa).

La reacción de conversión de azúcares reductores a etanol se siguió mediante la medición de los siguientes parámetros: Densidad, ${ }^{\circ} \mathrm{Brix}$ y/o ${ }^{\circ}$ Baumé, para los diferentes tiempos de avance de reacción (Figura 3).

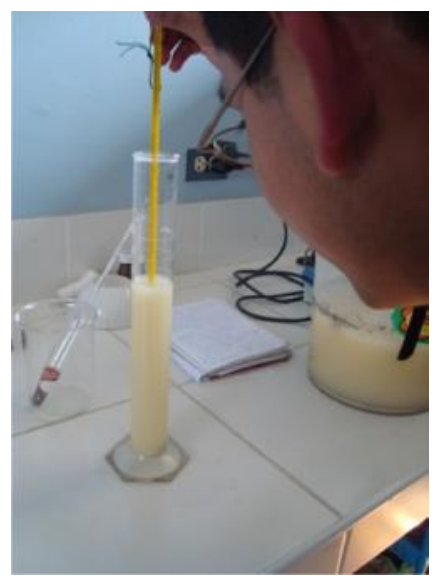

Fig. 3 Medición de parámetros durante la fermentación.

En cada experiencia se registraron los siguientes datos:

- Masa del jugo después de la molienda.

- Masa del bagazo de caña después de la molienda.

- $\mathrm{N}^{\mathrm{o}}$ Reynolds, Temperatura y $\mathrm{pH}$ del fermentador.

- Volumen del jugo antes y después de la fermentación.
- Temperatura, Densidad, ${ }^{\circ}$ Brix y/o ${ }^{\circ}$ Baumé del jugo antes, durante y después de la fermentación.

- Volumen, Densidad y/o ${ }^{\circ} \mathrm{GL}$ del etanol obtenido durante la destilación del mosto fermentando.

De todas las experiencias realizadas, sólo tres fueron seleccionadas (Figura 4) con el objetivo de comparar las variaciones de las eficiencias de proceso resultantes para diferentes tipos de tratamiento previo de las materias primas (jugo de caña de azúcar y levadura de uva quebranta).

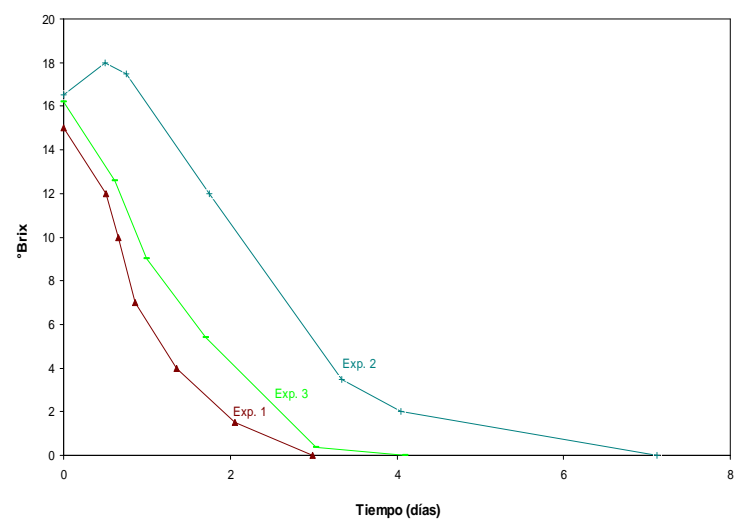

Fig. 4 Seguimiento del avance de reacción durante la fermentación para las experiencias seleccionadas.

La primera experiencia seleccionada (Exp. 1) siguió la metodología descrita líneas arriba, sin ningún tratamiento previo de las materias primas. La segunda experiencia seleccionada (Exp. 2) consistió en un tratamiento previo del jugo de caña de azúcar, para lo cual se efectuó un calentamiento a $95{ }^{\circ} \mathrm{C}$ y se dejó enfriar hasta $44{ }^{\circ} \mathrm{C}$ (ciclo de esterilización). Para determinar el procedimiento de esterilización óptimo se realizó un ensayo de laboratorio (descrito en los análisis y resultados citados posteriormente) en el que a cada muestra obtenida se le efectuó un análisis microbiológico, desarrollado con el apoyo del equipo del Dr. Abad Flores Paucarima de la UNMSM [5].

La tercera experiencia seleccionada (Exp. 3) fue realizada con las mismas condiciones de esterilización que la segunda para estandarizar un contenido mínimo de microorganismos presentes 
en el jugo de caña de azúcar, pero además se trató la levadura usada, aislando sólo dos cepas de la misma (cepa mixta) por medio de métodos microbiológicos [6], realizados también con la colaboración del equipo del Dr. Abad Flores Paucarima. De esta manera, se consiguió evidenciar el efecto neto del aislamiento.

\section{RESULTADOS Y DISCUSIÓN}

\section{Proceso experimental}

En la Tabla 1 se resumen las condiciones experimentales y los resultados obtenidos para cada corrida seleccionada. La conversión del sustrato alcanzada en cada experiencia fue total, $100 \%$, es decir, que se llegó a obtener $0{ }^{\circ}$ Brix en cada mosto fermentado.

El rendimiento teórico de la primera experiencia seleccionada fue de $74 \mathrm{~L}$ etanol / TM caña de azúcar con un rendimiento de la caña usada de 0,62 L jugo extraídos / $\mathrm{kg}$ caña de azúcar. El rendimiento teórico de la segunda experiencia seleccionada fue de $72 \mathrm{~L}$ etanol / TM caña de azúcar con un rendimiento de la caña usada de 0,60 L jugo extraídos / $\mathrm{kg}$ caña de azúcar. Asimismo, el rendimiento teórico de la tercera experiencia seleccionada fue de $67 \mathrm{~L}$ etanol / TM caña de azúcar con un rendimiento de la caña usada de 0,62 L jugo extraídos / kg caña de azúcar.

Los cálculos de rendimiento teórico fueron obtenidos haciendo uso de las reacciones estequiométricas globales (1) y (2).

Hidrólisis de la sacarosa.-

$\mathrm{C}_{12} \mathrm{H}_{22} \mathrm{O}_{11}+\mathrm{H}_{2} \mathrm{O} \rightarrow \mathrm{C}_{6} \mathrm{H}_{12} \mathrm{O}_{6}+\mathrm{C}_{6} \mathrm{H}_{12} \mathrm{O}_{6}$

Sacarosa Agua Glucosa Fructuosa

Degradación de la glucosa y/o fructuosa.-

$\begin{array}{cr}2 \mathrm{C}_{6} \mathrm{H}_{12} \mathrm{O}_{6} \stackrel{\text { Enzima }}{\longrightarrow} 4 \mathrm{C}_{2} \mathrm{H}_{5} \mathrm{OH}+4 \mathrm{CO}_{2} \\ (2)^{\text {Glucosa }} & \text { Etanol Gas Carbónico }\end{array}$

Tabla 1. Condiciones experimentales y resultados obtenidos para cada corrida seleccionada.

\begin{tabular}{|c|c|c|c|c|c|c|c|c|c|c|}
\hline Exp & $\begin{array}{l}\text { Levadura } \\
\text { usada como } \\
\text { inóculo }\end{array}$ & $\begin{array}{l}\text { Pretratamiento } \\
\text { del jugo de caña } \\
\text { de azúcar }\end{array}$ & $\begin{array}{l}\text { Temperatura } \\
\text { promedio } \\
\left({ }^{\circ} \mathrm{C}\right)\end{array}$ & $\begin{array}{l}\text { "Brix de } \\
\text { jugo a } \\
\text { fermentar }\end{array}$ & $\begin{array}{l}\text { "Brix de } \\
\text { mosto } \\
\text { fermentado }\end{array}$ & $\begin{array}{l}\text { Rendimiento } \\
\text { de la caña } \\
\text { usada }\end{array}$ & $\begin{array}{l}\text { Rendimient } \\
\text { o teórico }\end{array}$ & $\begin{array}{l}\text { Grado } \\
\text { alcohólico } \\
\text { de mosto } \\
\text { fermentado }\end{array}$ & $\begin{array}{l}\text { Rendimiento } \\
\text { real }\end{array}$ & $\begin{array}{l}\text { Eficiencia } \\
\text { de proceso }\end{array}$ \\
\hline & & & & "Brix & "Brix & $\begin{array}{c}\text { L jugo extraídos } \\
\text { kg caña de } \\
\text { azúcar }\end{array}$ & $\begin{array}{l}\frac{\text { L etanol }}{\text { TM caña }} \\
\underline{\text { de azúcar }}\end{array}$ & $\%$ & 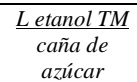 & $\&$ \\
\hline 1 & Pisco-Uni & Ninguno & 29,3 & 16,2 & 0,0 & 0,62 & 74 & $9,1 \%$ & 56,8 & 76,8 \\
\hline 2 & Pisco-Uni & $\begin{array}{l}\text { Calentamiento } \\
\text { a } 95^{\circ} \mathrm{C} \text { y se deja } \\
\text { enfriar hasta } \\
44^{\circ} \mathrm{C}\end{array}$ & 29,1 & 16,5 & 0,0 & 0,60 & 72 & $11,4 \%$ & 66,5 & $92,9 \%$ \\
\hline 3 & $\begin{array}{c}\text { Cepa } \\
\text { mixta } \\
\text { aislada }\end{array}$ & $\begin{array}{c}\text { Calentamiento } \\
\text { a } 95^{\circ} \mathrm{C} \text { y se deja } \\
\text { enfriar hasta } \\
44^{\circ} \mathrm{C}\end{array}$ & 28,5 & 15,0 & 0,0 & 0,62 & 67 & $10,2 ”$ & 62,5 & $93,5 \%$ \\
\hline
\end{tabular}

La glucosa y la fructuosa son isómeros. Cada una de ellas es sintetizada por acción de la biomasa (levaduras) para formar dos (2) moléculas de etanol y dos (2) moléculas de dióxido de carbono, así como otros productos secundarios (no deseados) en una mínima proporción. Con la destilación de la primera experiencia seleccionada, calculamos que el mosto fermentado tenía un grado alcohólico de $9,1 \%$ en volumen y un rendimiento real de $56,8 \mathrm{~L}$ etanol / TM caña de azúcar, resultando así un 76,8 $\%$ de eficiencia de proceso; con la destilación de la segunda experiencia seleccionada, calculamos que el mosto fermentado tenía un grado alcohólico de $11,4 \%$ en volumen y un rendimiento real de $66,5 \mathrm{~L}$ etanol / TM caña de azúcar, resultando así un 92,9 $\%$ de eficiencia de proceso; asimismo, con la destilación de la tercera experiencia seleccionada, calculamos que el mosto fermentado tenía un grado alcohólico de 10,2 \% en volumen y un rendimiento real de 62,5 L etanol / TM caña de azúcar, resultando así un 93,5\% de eficiencia de proceso (Tabla 1). 
Un análisis más detallado al comparar la primera y segunda experiencia seleccionada, nos permite afirmar que por el hecho de pretratar el jugo de caña de azúcar, aplicándosele un ciclo de esterilización, se pueden obtener 12,00 moles de etanol adicionales experimentales ó 11,73 L etanol / TM caña de azúcar, adicionales experimentales, lo cual, representa un 18,9 \% más de producción de etanol.

Por otro lado, la comparación de la segunda y tercera experiencia seleccionada, nos evidencia que por el hecho de utilizar una levadura aislada como inóculo (cepa mixta aislada), se pueden obtener 1,15 moles de etanol adicionales experimentales ó 0,40 L etanol / TM caña de azúcar, adicionales experimentales, lo cual representa un $0,6 \%$ más de producción de etanol.

\section{Esterilización del jugo de caña de azúcar}

Se realizaron los siguientes ensayos de esterilización del jugo de caña de azúcar en el Laboratorio de Operaciones Unitarias (Laboratorio $\mathrm{N}^{\circ}$ 23) de la FIQT-UNI, a diferentes temperaturas (Figura 5), para obtener un procedimiento de esterilización óptimo:

\section{$\checkmark$ Muestra 1: $75^{\circ} \mathrm{C}$ por 15 minutos \\ $\checkmark$ Muestra 2: $85^{\circ} \mathrm{C}$ por 15 minutos \\ $\checkmark$ Muestra 3: $95^{\circ} \mathrm{C}$ por 10 minutos \\ $\checkmark$ Muestra 4: $105^{\circ} \mathrm{C}$ por 10 minutos \\ $\checkmark$ Muestra 5: $110^{\circ} \mathrm{C}$ por 10 minutos}

Cuando la esterilización se realiza a partir de una temperatura de $95^{\circ} \mathrm{C}$ por 10 minutos, se elimina en su totalidad la concentración de levaduras presentes propias del jugo de caña de azúcar, quedando aún un contenido de bacterias, el cual es mínimo (menor de $10 \mathrm{ufc} / \mathrm{mL}$ ).

Una esterilización efectuada a $110{ }^{\circ} \mathrm{C}$ por 10 minutos da como resultado un jugo de caña de azúcar totalmente libre, no sólo de levaduras propias del mismo, sino también de las bacterias aerobias mesófilas viables.

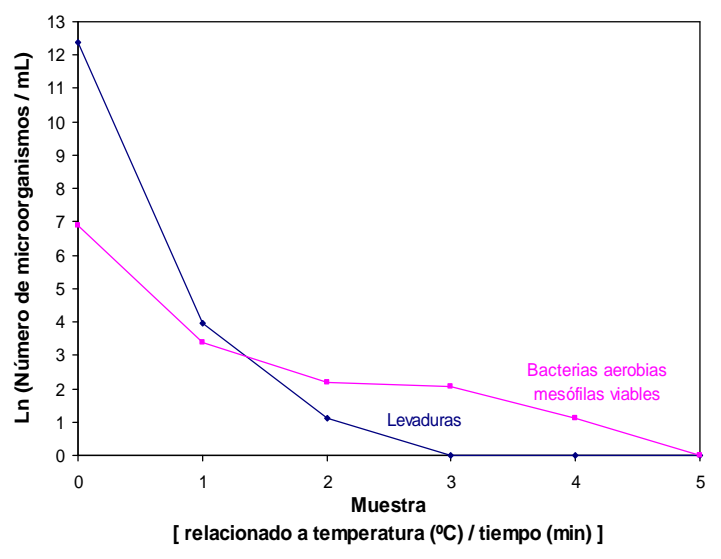

Fig.5 Resultados de los ensayos de esterilización del jugo de caña de azúcar.

Los medios sólidos de cultivo que se utilizaron para el conteo microbiológico de levaduras y bacterias aerobias mesófilas viables fueron el caldo agar papa dextrosa (APD) y el caldo agar plate count (APC), respectivamente.

\section{Aislamiento de la cepa mixta de la levadura de uva quebranta}

Mediante el empleo del caldo de cultivo APD, en la levadura de uva quebranta se llegaron a reconocer culturalmente y aislar más de dos cepas diferenciadas de la misma especie Saccharomyces cerivisiae identificada. De todas las cepas aisladas, se mezclaron sólo dos de ellas para realizar el preparado mixto que se utilizó como inóculo para la tercera experiencia seleccionada.

\section{CONCLUSIONES}

Con las tres experiencias expuestas en este trabajo, realizadas en el reactor Batch (45 L) del Laboratorio de Operaciones Unitarias y Corrosión (Laboratorio $\mathrm{N}^{\circ}$ 23-A) de la FIQT-UNI, se pudo obtener bioetanol hidratado a partir de jugo de caña de azúcar usando levadura de uva quebranta, subproducto del proceso Pisco-UNI, garantizando una conversión total del sustrato por medio de establecer un número de Reynolds adecuado y mantener unas condiciones estables de operación.

Se logró obtener un procedimiento de esterilización óptimo para el jugo de caña de azúcar, lo cual, permitió además una estandarización de dicho jugo que es indispensable para un proceso continuo, en 
el sentido que siempre se garantiza un contenido mínimo de microorganismos presentes para las subsiguientes etapas del proceso.

El hecho de pretratar el jugo de caña de azúcar, aplicándosele un ciclo de esterilización, permite obtener una mejor eficiencia de proceso que si no se efectuara, generando una mayor producción de etanol ( $18,9 \%$ adicional).

El hecho de aislar la levadura de uva quebranta permite obtener una mejor eficiencia de proceso que si no se realizara, generando una mayor producción de etanol ( $0,6 \%$ adicional).

Cabe señalar que para fines de escalamiento industrial, ambos tratamientos previos realizados se deberán analizar comparando todos los costos involucrados que representa pretratar el jugo de caña de azúcar y/o aislar la levadura de uva quebranta para un volumen determinado de producción, de tal manera de optar por uno de ellos o por ambos.

\section{AGRADECIMIENTOS}

A todos los docentes y alumnos investigadores que se comprometieron con los proyectos "Elaboración y especificaciones técnicas del pisco peruano" y "Producción de bioetanol a nivel banco usando insumos nacionales", realizados en la FIQT de la UNI desde el año 2004 al 2010.

Al Instituto General de Investigación de la UNI (IGI - UNI) y al Instituto de Investigación de la FIQT (II - FIQT), entes que apoyaron y promovieron el proyecto de investigación aplicada "Producción de bioetanol a nivel banco usando insumos nacionales" -en el cual se enmarca el desarrollo del presente trabajo-, por la trascendencia del mismo y los frutos que daría a nuestra alma máter y al Perú.

Al Laboratorio de Microbiología Ambiental y Biotecnología de la Facultad de Ciencias Biológicas de la UNMSM, donde se realizaron los análisis microbiológicos que enriquecieron la investigación biotecnológica.

\section{REFERENCIAS}

1. Sánchez, O. J., Cardona, C. A., "Producción biotecnológica de alcohol carburante $\mathrm{I}$ :
Obtención a partir de diferentes materias primas". Revista Interciencia, Vol. 30, $\mathrm{N}^{\mathrm{o}} 11$, pp. 671 - 678, Caracas, Venezuela, 2005.

2. Organização Banco Nacional de Desenvolvimento Econômico e Social (BNDES) e Centro de Gestão e Estudos Estratégicos (CGEE), "Bioetanol de cana-deaçúcar: energía para o desenvolvimento sustentable". BNDES, pp. 67 - 83, Rio de Janeiro, Brasil, 2008.

3. Lagos Liberato, C., Ramesh Barrueto Yanque, J., "Estudio de pre-factibilidad para instalar una planta de producción de bioetanol hidratado a partir de la caña de azúcar usando levadura de uva quebranta". Facultad de Ingeniería Química y Textil (FIQT), Universidad Nacional de Ingeniería (UNI), Lima, Perú, 2011.

4. De La Cruz Azabache, M. R., Marcelo Astocondor, D. A., "Proceso para la elaboración de aguardiente de uvas", C. I. P .7 C12G 3/12; B01D 3/00 (INDECOPI), Lima, Perú.

5. Abad Flores P., y Colaboradores, "Informe de análisis microbiológicos de los ensayos de esterilización". Universidad Nacional Mayor de San Marcos (UNMSM), Lima, Perú, 2009.

6. Mas, A., Torija, M. J., Beltrán, G., Novo, M., Hierro, N., Poblet, M., Rozés N., Guillamón, J. M., "Selección de levaduras". Unitat d'enologia del Centre de Referència en Tecnologia dels Aliments, Facultad de Enología de Tarragona, Universidad Rovira i Virgili, pp. 39 - 44, España.

\section{INFRAESTRUCTURA}

\section{Laboratorios}

Para el desarrollo del presente trabajo se utilizaron los siguientes laboratorios:

- Laboratorio de Operaciones Unitarias y Corrosión (Lab. $\mathrm{N}^{\mathrm{o}}$ 23-A) de la FIQTUNIVESIDAD NACIONAL DE INGENIERIA.

- Laboratorio de Operaciones Unitarias (Lab. $\mathrm{N}^{\circ}$ 23) de la FIQT-UNIVERSIDAD NACIONAL DE INGENIERIA.

- Laboratorio de Microbiología Ambiental y Biotecnología de la Facultad de Ciencias Biológicas de la UNMSM. 


\section{Equipos sofisticados}

Asimismo, para el desarrollo del presente trabajo se emplearon los siguientes equipos sofisticados:

- Microscopio óptico de fases.

- Fermentador Batch.
- Destilador Batch.

Correspondencia: mario45@gmail.com

Recepción de originales: noviembre 2012 Aceptación de originales: abril 2013 